\title{
May Roger roll on ...
}

Roger Williams has contributed so constantly, voluminously, and effectively to our knowledge of liver diseases that one inevitably thinks of him as a permanent feature in our firmament - eternally youthful, a constant mainstay of hepatology. It is quite impossible to think of Roger without calling up a sense of his ebullience, enthusiasm, and great good humour that sparkles in every gathering and that stimulates excitement about him and his ideas. Although he now approaches with honour his seventh decade, and his unit completes its first quarter century of major contributions, it is quite impossible to think of him as a grand old master relaxed in his professorial chair well above the battle. No, we all are certain that Roger discarded his scabbard years ago and will never stoop to retrieve it, that he will always be a stimulating and dependable leader - young in heart and strong in counsel in whom we can confidently put our trust and from whose insightful and cogent judgments we can all gain new insights, energy, and guidance. One cannot help but to have noticed the catholicity of his thinking and the far ranging appeal of his teaching. Needless to say, of course, his writings and achievements have gained general recognition that has brought him students from near and far. Only last year alone, for example, more than 40 of these young people authored contributions from his Liver Unit at King's College Hospital!

It should be stressed that this attractiveness for students is not attributable solely to the obvious magnetic appeal of his work in liver transplantation, which looms so large on the world stage of research and clinical advance with its exciting and promising implications for the future control of otherwise fatal hepatic failure from any causes. Study of Roger's bibliography (which encompasses over 1000 contributions) and citation record during the last three decades reveals not only the impact of this work, but also a fascinating intellectual thrust in his explorations of much more than clinical phenomena - exciting as these have been. Over this period he has made himself an outstanding figure in the study of haemachromatosis and primary biliary cirrhosis, of hepato- splanchnic haemodynamics and immune mechanisms in liver diseases, of fulminant liver failure, and of a wide variety of pharmacological responses that have proved of help in controlling various hepatic dysfunctions. With this, he has devoted an enormous amount of energy towards achieving techniques for support or substitution of liver function. His ability as a superb clinician has illuminated and determined the quality and relevance of his scientific contributions that have benefited all of us.

Finally, one should say something about the ambience Roger has always created about him at home and in the clinic or laboratory where his cheerfulness, competence, drive, and devotion to the task in hand carry all and everyone forward on a voyage of discovery. This trait is characterised by a certain attractive romanticism. It is not by accident that we all enjoyed ourselves so thoroughly when Roger played host at the Liver Meetings in Southampton in 1983 where we found ourselves in what one might call 'Kipling country' with an honest-to-goodness smugglers' cave at hand, a glimpse of the storied Isle of Wight and the harbour where:

Yes, weekly from Southampton,

Great steamers, white and gold,

Go rolling down to Rio

(Roll down - roll down to Rio!)

And I'd like to roll to Rio

Some day before I'm old!

May Roger roll on and on as he will and as he pleases long before he's old!

R PREISIG

Department of

Clinical Pharmacology,

University of Berne,

Murtenstasse 35,

Switzerland

S BRADLEY

Thomas Wynne Apartments A-516,

$200 N$ Wynnewood Avenue,

Wynnewood, PA 19096,

USA 